\title{
O ensino/aprendizagem de Língua Portuguesa a partir dos gêneros do discurso
}

Fabiana Giovani*

\section{Resumo}

$\mathrm{O}$ presente artigo nasce a partir de um curso de formação continuada oferecido pelo Programa Institucional de Bolsa de Iniciação à Docência (Pibid) da Universidade Federal do Pampa (Unipampa) aos professores de língua portuguesa da rede pública de Bagé, RS. O intuito da formação intitulada "O ensino/aprendizagem de Língua Portuguesa a partir dos gêneros do discurso" foi refletir sobre a importância que o texto ocupa no processo de ensino/aprendizagem da língua portuguesa. Para isso, retomamos alguns pontos teóricos, como: i) a mudança da nomenclatura da redação à produção de texto e a significação que comporta cada um dos termos; ii) a compreensão de gêneros a partir de Bakhtin (2003) e a transposição didática, segundo Schneuwly e Dolz (2004); iii) a importância de se pensar sobre as condições de produção de todo e qualquer texto. Por fim, os professores tiveram atividades práticas de escrita fundamentadas na teoria e que evidenciaram que trabalhar com o texto é deixar que a "vida" invada o espaço da sala de aula.

Palavras-chave: Ensino/aprendizagem de Língua Portuguesa. Gêneros do discurso. Sequência didática.

\section{Introdução}

Pensar a aula de língua portuguesa, hoje, no vigor do século XXI, no contexto escolar brasileiro, é assumir a importância do texto como objeto fundamental no processo ensino/aprendizagem. Historicamente, sabemos que esse posicionamento não é novo. Desde os anos 1970/1980 - tempo que não está tão longe quanto parece -, o ensino de Língua Portuguesa passou a ser o foco de muitas discussões e mudanças, o que gerou um conjunto de propostas de ensino elaboradas com o objetivo de criar alternativas pedagógicas que superassem o fracassado ensino da "gramática"

De acordo com Pietri (2007), observou-se, inicialmente, a emergência do interesse da própria academia pela pro-

Professora Adjunta no Departamento de Metodologia de Ensino (MEN) da Universidade Federal de Santa Catarina (UFSC). E-mail: fabiana.giovani@ufsc.br

Data de submissão: set. 2020 - Data de aceite: nov. 2020 http://dx.doi.org/10.5335/rdes.v16i3.11235 
dução escrita de caráter escolar. Estudos que se focaram sobre redações escolares concluíram por unanimidade que a escola não levava o aluno a se colocar criticamente, mas lhe oferecia modelos e estratégias de preenchimento (LEMOS, 1977), a fim de cumprir a tarefa de produzir a redação. Algo estava errado e os estudos debruçaram-se sobre a busca de soluções possíveis, caminhos novos para serem trilhados.

No interior deste quadro de reflexões e mudanças, houve uma tentativa de transformar, inclusive a própria nomenclatura e toda a base teórica carregada por ela: da redação à produção de textos. Osakabe (1977, p. 58) já demonstrava preocupações com relação à prática de redação, evidenciando uma necessidade de mudança:

[...] o exercício de redação é mais que um adestramento: é o favorecimento de uma atitude no sujeito, atitude essa que não se reduz à sintaxe gramaticalmente correta, mas que envolve necessariamente o debate, a crítica, a informação, a leitura.

A terminologia "produção de textos" trouxe para a prática em sala de aula uma nova concepção de lingua(gem), sendo esta considerada agora uma forma de interação. Assim, mais do que possibilitar uma transmissão de informações de um "emissor" a um "receptor", a linguagem passou a ser compreendida como um lugar de interação humana.
Embora haja uma extensa bibliografia sobre o tema em questão, inclusive é sabido que o texto como objeto de ensino é tematizado pelos documentos oficiais como, por exemplo, os PCNs (BRASIL, 1997) e o referencial curricular estadual Lições do Rio Grande (RIO GRANDE DO SUL, 2009), é ainda questionável entre os professores atuantes a compreensão que vai desde o que é, de fato, um texto até as suas inúmeras possibilidades de trabalho efetivo em sala de aula.

Por esse motivo, este artigo retoma o trabalho realizado em um programa de formação continuada na área de Letras oferecido pelo Programa Institucional de Bolsa de Iniciação à Docência (Pibid) ${ }^{3}$, cuja temática foi o ensino através dos gêneros do discurso. Vale salientar que se tratou de dois encontros com espaço de aproximadamente um mês entre eles.

O artigo está organizado em três seções. Na primeira, apresentamos a teoria que fundamentou nossa proposta didática. A segunda traz o relato do diálogo com os professores e as propostas de escrita lançadas. Finalizamos com algumas considerações finais.

\section{A teoria que permeia a prática}

Esta seção traz os principais pilares teóricos que sustentaram as oficinas práticas. 


\section{O texto como objeto de ensino}

Inicialmente, é preciso deixar claro que conceber o texto como unidade de ensino/aprendizagem envolve o reconhecimento de que podemos aprender palavras sem aprender seus sentidos ${ }^{4}$. Assim, o texto (oral ou escrito) é o lugar das correlações, uma vez que é nele que organizamos palavras em unidades maiores para construir informações cujo sentido torna-se compreensível apenas na unidade global do texto.

No entanto, o que temos em circulação são textos que dialogam com outros textos sem os quais não existiriam. Como diz Bakhtin (2003), somente o Adão mítico que chegou com a primeira palavra num mundo virgem, portanto, só ele realmente poderia evitar por completo esta mútua orientação dialógica do discurso alheio para o objeto. Nas palavras de Geraldi e Citelli (2004, p. 22):

Conceber o texto como unidade de ensino/ aprendizagem é entendê-lo como um lugar de entrada para este diálogo com outros textos, que remetem a textos passados e que farão surgir textos futuros. Conceber o aluno como produtor de textos é concebê-lo como participante ativo deste diálogo contínuo: com textos e com leitores.

O trecho supracitado, além de evidenciar que há um continuum de textos, que se relacionam entre si, aponta para a mudança de eixo com relação aos alunos, sujeitos. Aqui, o sujeito não é visto nem como fonte de seu dizer, nem como assujeitado às condições e às limitações históricas. Contrariamente, o sujeito é entendido como produto de uma herança cultural e suas ações sobre ela. Dessa forma, um sujeito pode repetir atos e gestos, mas pode também construir novos atos e gestos, num movimento histórico no qual repetição e criação caminham de mãos dadas.

Além da concepção de sujeito, conceber o texto como foco do processo ensino/ aprendizagem implica uma mudança na própria sala de aula. Esta deixa de ser um lugar de transmissão para se tornar um lugar de construção, de interação verbal. Então, temos em tese um lugar onde ocorre o diálogo entre sujeitos - professor e alunos - portadores de diferentes saberes que se confrontam entre si e com os conhecimentos historicamente sistematizados ${ }^{5}$.

Rojo (2006) atenta para o fato de que conceber o texto como objeto de ensino ou como material sobre o qual se desdobra um ensino processual significa reconhecer um deslocamento dos eixos do ensino-aprendizagem de língua materna: passamos de um ensino normativo, no qual se prioriza a análise da língua e a gramática, para um ensino procedimental, em que os usos da língua escrita, em leitura e escrita, são também valorizados ${ }^{6}$.

Historicamente, vemos uma mudança na própria noção de texto enquanto "objeto" de ensino. Quando o texto passa a 
ser referenciado no ensino, algumas propriedades são priorizadas, principalmente as estruturais. Assim, os "modelos" fixos de textos escolares por excelência eram denominados: narração, descrição e dissertação. Além disso, neste momento, nas palavras de Rojo (2006, p. 09):

Ensina-se a forma global dos textos: por exemplo, uma tese - e/ou antítese - desenvolvida por meio de argumentos sustentados e hierarquizados, na dissertação; ou um cenário que dá fundo a uma situação inicial que, ao complicar-se - e resolver-se -, vai dar ensejo à intriga da narrativa. Ensinam-se essas formas globais, na produção, para obter textos mais interessantes, coesos e coerentes, e, na leitura, por serem necessárias e participantes de certas estratégias importantes, tais como a antecipação e a checagem e inferência, o resumo, etc. Ao mesmo tempo, mantêm-se aulas de análise epi ou metalinguística, em paralelo aos dois eixos procedimentais da área.

O ensino das propriedades do texto na sala de aula gerou alguns problemas. $\mathrm{O}$ primeiro deles foi o fato de que houve praticamente uma "gramaticalização" dos eixos de uso. Isso quer dizer que o texto passou a ser pretexto não somente para o ensino da gramática tradicional, mas também para uma gramática "textual”, disseminando a falsa ideia de que quem soubesse as regras saberia como "proceder".

Outro problema gerado por esse tipo de abordagem foi o apagamento da heterogeneidade constitutiva de um texto. Havia uma tentativa de homogeneizar a escrita a fim de classificá-la em uma forma tipológica. Isso fica fácil de ser aplicado a um texto cuja estrutura pode ser reconhecida canônica como uma narrativa de aventura ${ }^{7}$, mas era difícil colocar na estrutura tipológica um artigo de opinião que utilizasse como estratégia argumentativa o relato, por exemplo.

Aos dois problemas apresentados, junta-se o fato de que esse tipo de abordagem textual não levava em consideração elementos como produção e circulação dos textos, permanecendo mais ligado ao conteúdo e às estruturas. Rojo (2006) liga a este problema o fato de que, no Brasil, tem-se visto bastante preocupação e discussão a respeito do fato de que as práticas escolares brasileiras tendem a formar leitores, ao final do ensino médio, com apenas as capacidades mais básicas de leitura, ligadas à extração simples de informação de textos relativamente simples.

É esta realidade que convoca a noção de gêneros discursivos - orais e escritos - para o cenário educacional como uma possibilidade de favorecer o ensino de leitura e produção de textos. O novo termo emprestado da teoria do filósofo Bakhtin (2003) vem acompanhado de uma virada discursiva ou enunciativa no uso do texto na sala de aula. O objetivo, então, é enfocar o texto em seu funcionamento e em seu contexto de produção/leitura, evidenciando as significações geradas mais do que as propriedades formais que dão suporte a funcionamentos cogniti- 
vos. Essa nova abordagem ganha força nos documentos oficiais, o que pode ser visto na seguinte passagem dos $\mathrm{PCNs}$, $3^{\circ}$ e $4^{\circ}$ ciclos do ensino fundamental, por exemplo:

Os textos organizam-se sempre dentro de certas restrições de natureza temática, composicional e estilística, que os caracterizam como pertencentes a este ou aquele gênero. Desse modo, a noção de gênero, constitutiva do texto, precisa ser tomada como objeto de ensino (BRASIL, 1997, p. 23).

\section{O trabalho com os gêneros na escola}

Podemos dizer, então, que Bakhtin (2003) foi o primeiro a empregar a palavra "gêneros" com um sentido mais amplo, referindo-se também aos textos que empregamos nas situações cotidianas de comunicação. Essa noção de gênero foi "adotada" pelo discurso pedagógico e aí entram em cena outros nomes importantes como Joaquim Dolz e Bernard Schneuwly. Estes e seu grupo de pesquisa são psicólogos e têm um objeto de pesquisa: o ensino.

O grupo compreende o gênero como um instrumento, que possibilita exercer uma ação linguística sobre a realidade. Para eles, o uso de uma ferramenta (instrumento) resulta em dois efeitos diferentes de aprendizagem: por um lado, amplia as capacidades individuais do usuário; por outro, amplia seu conhecimento a respeito do objeto sobre o qual a ferramenta é utilizada. Assim, para o grupo, no plano da linguagem, o ensino dos diversos gêneros que socialmente circulam entre nós, além de ampliar sobremaneira a competência linguística e discursiva dos alunos, aponta-lhes inúmeras formas de participação social que eles, como cidadãos, podem ter, fazendo uso da linguagem.

Este grupo inova ao pensar em forma de progressão no trabalho com os gêneros, na escola. Assim, partem de conceitualizações linguísticas e psicológicas para criar um enfoque de agrupamentos de gêneros.

As tipologias do discurso elaboradas em linguística e psicologia, durante um certo tempo, puderam ser consideradas como uma saída promissora. Muito rapidamente, verificou-se que, mesmo trazendo importantes conhecimentos novos sobre o funcionamento da linguagem e, logo, elementos que devem ser levados em consideração no trabalho com textos, essas tipologias sofriam, do ponto de vista de sua aplicação didática, de duas limitações importantes: a) seu objeto não é o texto, e ainda menos o gênero do qual todo texto é um exemplar, mas operações de linguagem constitutivas do texto, tais como a ancoragem enunciativa e a escolha de um modo de apresentação ou de tipos de sequencialidades; b) por isso mesmo, a análise se exerce sobre subconjuntos particulares de unidades linguísticas que formam configurações, traduzindo as operações de linguagem postuladas. As tipologias discursivas não podem, por si sós, fornecer uma base suficientemente ampla para elaborarmos progressões, que ficariam forçosamente parciais, tocando somente em certos aspectos do funcionamento da linguagem (SCHNEUWLY; DOLZ, 2004, p. 58). 
A partir desta ideia, apresentamos o Quadro 1, afirmando que a originalidade da estratégia não reside absolutamente nos agrupamentos propostos, uma vez que estes são semelhantes a muitos outros, mas inovam no fato de trabalharem no nível dos gêneros e na tentativa de definir as "capacidades de linguagem globais" em relação às tipologias existentes.

Proposta provisória de agrupamento de gêneros ${ }^{8}$.

Quadro 1 - Agrupamentos de gêneros

\begin{tabular}{|c|c|}
\hline $\begin{array}{l}\text { Domínios sociais de comunicação - } \\
\text { ASPECTOS TIPOLÓGICOS } \\
\text { Capacidades de linguagem dominantes }\end{array}$ & Exemplos de Gêneros Orais e Escritos \\
\hline $\begin{array}{c}\text { Cultura literária ficcional } \\
\text { NARRAR } \\
\text { Mimesis da ação através da criação da intriga no } \\
\text { domínio do verossímil }\end{array}$ & $\begin{array}{l}\text { Conto maravilhoso - Conto de fadas - Fábula - } \\
\text { Lenda - Narrativa de aventuras - Narrativa de } \\
\text { enigma - Biografia romanceada - Romance }- \text { Novela } \\
\text { fantástica - Conto - Paródia - Advinha - Piada - ... }\end{array}$ \\
\hline $\begin{array}{c}\text { Documentação e memorização das ações humanas } \\
\text { RELATAR } \\
\text { Representação pelo discurso de experiências } \\
\text { vividas, situadas no tempo }\end{array}$ & $\begin{array}{l}\text { Relatos de experiência vivida - Notícia - Relatos } \\
\text { de viagem - Reportagem - Diário íntimo - Crônica } \\
\text { mundana - Testemunho - Crônica esportiva } \\
\text { - Anedota - Autobiografia - Curriculum vitae - } \\
\text { Historiais - Biografia - Relatos históricos - ... }\end{array}$ \\
\hline $\begin{array}{l}\text { Discussão de problemas sociais controversos } \\
\text { ARGUMENTAR } \\
\text { Sustentação, refutação e negociação de tomadas } \\
\text { de posição }\end{array}$ & $\begin{array}{l}\text { Textos de opinião - Editorial - Diálogo argumentativo } \\
\text { - Discurso de defesa (advocacia) - Carta ao leitor } \\
\text { - Requerimento - Carta de reclamação - Carta de } \\
\text { solicitação - Ensaio - Resenhas críticas - Debate } \\
\text { regrado - ... }\end{array}$ \\
\hline $\begin{array}{c}\text { Transmissão e construção de saberes } \\
\text { EXPOR } \\
\text { Apresentação textual de diferentes formas de } \\
\text { saberes }\end{array}$ & $\begin{array}{l}\text { Texto expositivo - Conferência - Artigo enciclopédico } \\
\text { - Entrevista de especialista - Texto explicativo - } \\
\text { Tomada de notas - Resenhas - Relatório científico } \\
\text { - Relato de experiências (científicas) - ... }\end{array}$ \\
\hline $\begin{array}{c}\text { Instruções e prescrições } \\
\text { DESCREVER AÇÕES } \\
\text { Regulação mútua de comportamentos }\end{array}$ & $\begin{array}{l}\text { Instruções de uso - Regras de jogo - Instruções de } \\
\text { montagem - Receita - Regulamento - Consignas } \\
\text { diversas - Textos prescritivos - ... }\end{array}$ \\
\hline
\end{tabular}

Fonte: Schneuwly e Dolz (2004).

Sobre esses agrupamentos, os autores ainda ressaltam que as formas como estão definidos não são estanques uns com relação aos outros, uma vez que não é possível classificar cada gênero de maneira absoluta em um dos agrupamentos propostos. No máximo, seria possível determinar certos gêneros que seriam os protótipos para cada agrupamento e que poderiam ser indicados para um instrumento didático. Assim, o quadro revela que esses agrupamentos parecem ser suficientemente diferentes uns dos outros para que seja possível definir, para cada um deles, algumas capacidades globais 
que se devem construir ao longo da escolaridade.

Dessa forma, a intenção dos autores com esse agrupamento é a de que se construam com os alunos, em todos os graus de escolaridade, instrumentos, visando ao desenvolvimento das capacidades necessárias para dominar os gêneros agrupados. Ressalvam ainda que a hipótese subjacente é a de que há uma afinidade suficientemente grande entre os gêneros agrupados, para que transferências se operem facilmente de um a outro, hipótese fundada sobre a ideia de uma dominância no que concerne às capacidades psicológicas implicadas em cada agrupamento ${ }^{9}$.

\section{As condições de produção de um texto}

É próprio da linguagem seu caráter interlocutivo. Estudos apontam que a interlocução - interação do eu com o outro - é o espaço onde ocorre a constituição de sujeitos e de produção de linguagem que acaba por permear relações importantes e necessárias como os encontros, desencontros, confrontos de posições que, ao tornarem-se públicas, evidenciam toda uma carga ideológica além de revelar a posição de cada indivíduo na sociedade.

Assim, sabemos que a língua, no seu uso prático, é inseparável de seu contexto e de seu conteúdo ideológico, e a forma linguística (signos) sempre se apresenta aos locutores no contexto de enunciações precisas, o que implica sempre em um contexto ideológico preciso. $\mathrm{Na}$ realidade, como apontam os estudos de Bakhtin (2003), não são palavras que pronunciamos ou escutamos, mas verdades ou mentiras, coisas boas ou más, importantes ou triviais, etc. Observamos, ainda, que o sentido da palavra não pode ser desvinculado de seu contexto, caso contrário, perde o seu real significado.

Sabemos que um dos objetivos da escola é criar condições para que a língua materna seja aprendida em algumas de suas modalidades especiais e ainda que comumente é considerada para este fim apenas a variedade "padrão", sendo ignoradas pela escola as outras formas de falar ou os muitos dialetos existentes no Brasil.

Isso decorre do fato de que, na situação escolar, existem relações rígidas e bem definidas nas quais o aluno, na maioria das vezes, é obrigado a escrever dentro de padrões estipulados previamente pela instituição escolar, além de saber antecipadamente que seu texto será julgado, avaliado.

Nesta perspectiva de trabalho, a linguagem perde seu caráter interlocutivo e o interlocutor, que poderia ser, como propõe Britto (2004, p. 118), "real ou imaginário, individual ou coletivo, pode estar mais ou menos próximo", acaba sendo anulado e torna-se o professor o 
principal (para não dizer o único) leitor do texto produzido.

Assim, o que propomos é que a escola não se apresente mais como interlocutor privilegiado do estudante e, nesta posição, ser a única e a responsável em determinar a própria imagem do aluno e de seu discurso. Como mostra Osakabe (2004, p. 26):

Ser sujeito do discurso seria conferir a cada enunciado produzido a relevância identificadora que lhe dá tanto um papel substantivo no contexto em que é produzido quanto confere uma identidade específica ao seu enunciador. Em outros termos, o discurso assim produzido seria original e único na sua relação com o contexto e com o interlocutor.

O professor não pode ser o principal talvez o único - leitor do texto do aluno ${ }^{10}$. Como vimos nos parágrafos anteriores, dentro da escrita podem-se identificar diferentes tipos de interlocutor: ele pode ser preciso, definido como numa carta; pode ser genérico como num jornal; pode ser virtual como na ficção literária. $\mathrm{O}$ importante é a consciência de que a presença do interlocutor no discurso não é algo neutro, sem valor.

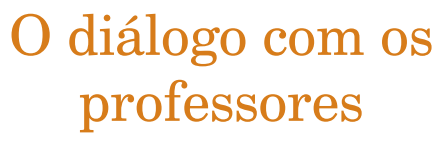

Esta seção traz o relato do diálogo com os professores através dos dois encontros realizados.

\section{Prática 1}

No primeiro encontro com os professores em formação, fizemos uma simulação interessante. Assim que a ministrante se apresentou, lançou a seguinte proposta: vocês vão escrever uma "crônica". Sem maiores detalhes. Curiosamente, todos a olharam com estranhamento, mas na posição de "alunos" - aceitaram a tarefa "escolar" e começaram a escrever. Foi uma experiência importante porque muitos olhavam para a ministrante com ar de questionamento, outros brincavam com o lápis e outros saíram a escrever. Passados dez minutos, foi questionado se eles tinham contexto para escrever tal texto. A ministrante questionou se eles cumpriam uma "tarefa escolar" sem questionamentos e, como proposta de reflexão, perguntou quantas vezes os seus e tantos outros alunos se sentiam daquela forma na sala de aula. Retomou-se a ideia de Geraldi (2002) de que, para escrever, o sujeito autor precisa ter o que dizer, ter uma razão para que dizer o que tem a dizer, ter para quem dizer, e aí escolher a melhor estratégia para o seu propósito.

A partir daí, começou o encaminhamento da atividade, de fato. Levamos para a leitura o texto " $\mathrm{Na}$ fila da liberdade”, de Mário Prata. Por conceber: i) que o texto enquanto unidade de ensino/ aprendizagem é o lugar de entrada para o diálogo com outros textos, que remetem a 
textos passados e que farão surgir textos futuros; e ii) que o aluno como produtor de textos é o participante ativo deste diálogo contínuo: com textos e com leitores, não dissemos que se tratava de uma crônica.

Após a leitura, mediamos uma discussão e uma reflexão a partir do olhar para as características relativamente estáveis do gênero - tema, estrutura e estilo - e, neste momento, apareceu a nomenclatura "crônica"11.

A ideia defendida junto aos professores é que só podemos escrever determinado gênero a partir do momento que conhecemos as suas características, e isso só ocorre quando circulamos por sua esfera de circulação e por ele próprio enquanto leitores. É claro que na oficina não teríamos tempo de efetivar essa circulação, mas a sugestão foi fazer isso acontecer, de fato, na sala de aula. Em outras palavras, o aluno precisa conhecer o gênero não só em seu funcionamento, mas também em sua esfera de circulação para ter condições de ser autor e atender a uma proposta de escrita.

Após, aproveitando a temática em voga na mídia no dia da oficina, a tragédia ocorrida no Japão em 11 de março de 2011, levamos uma carta ao leitor publicada no jornal Folha de S. Paulo que respondia a uma charge do cartunista João Montanaro, de 14 anos. O desenho de uma onda carregando destroços ${ }^{12}$, veiculada um dia após o tsunami que devastou o norte do Japão, foi o tema mais comentado nas cartas enviadas ao jornal nos dias seguintes.

Seguem a imagem e a carta ao leitor:

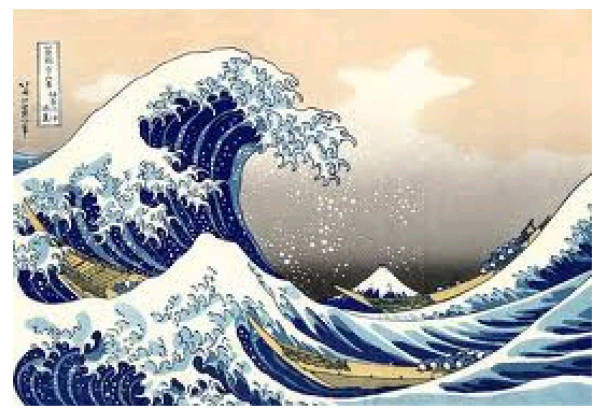

Xilogravura de Katsushika Hokusai

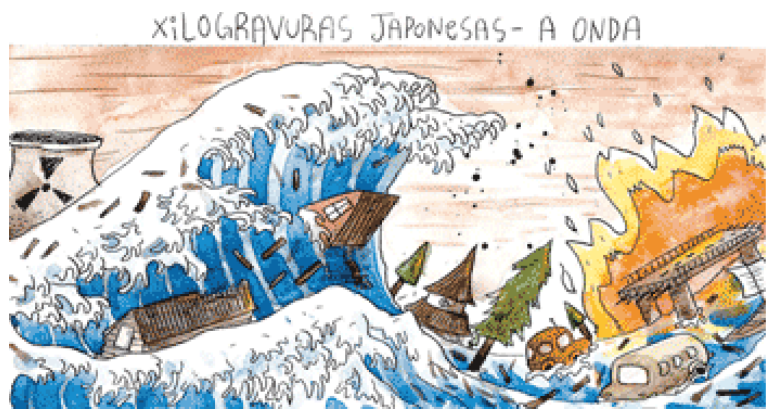

Charge de João Montanaro publicada em 12/03/2011

Carta ao leitor - Folha de S. Paulo - 13/03/2011

Impressionante, infeliz, impiedosa e sem nenhuma sensibilidade a charge editada por este jornal na pág. A2 de ontem. Como pode um jornal como a Folha permitir esta divulgação em um momento tão infeliz? $O$ autor nem ao menos se identifica no desenho, uma vergonha. O momento pelo qual passam nossos irmãos japoneses não permite tamanha insensibilidade. RUBENS MANOEL PARANHOS BELLO (Jandira, SP). 
A charge e a carta ao leitor geraram uma discussão entre os professores não só sobre a temática que gerou posicionamentos distintos, mas sobre a própria função social de cada um dos gêneros envolvidos. No papel de mediadores, trouxemos a voz do próprio criador da charge e de alguns críticos a partir de um texto de Diogo Bercito, também publicado no jornal:

"Minha intenção não era fazer uma piada", diz artista

João Montanaro já tinha decidido qual seria o tema da charge de sábado quando acordou na sexta-feira. Então, viu na televisão imagens de prédios se desfazendo em meio ao mar que avançava. "Não dava para fazer um desenho sobre política!", diz.

Ao decidir retratar o tsunami, Montanaro lembrou-se da xilogravura de Katsushika Hokusai. Foi uma das opções que ele enviou à Folha para aprovação e publicação. "Fiquei surpreso com as críticas", diz. "Acho que não entenderam a charge".

Apesar da má recepção, inclusive na escola, o garoto diz estar seguro da escolha. "Fiz o certo, minha intenção não era fazer uma piada".

O ilustrador Adão Iturrusgarai, que publica na Ilustrada, defende Montanaro. "É um desenho superimparcial. É inocente como o ilustrador, que é um jovenzinho", diz. "De mau gosto foi a tragédia em si". E completa: "O humor funciona por conta dessa contraonda, desse mau humor e da burrice dos críticos".

Para o artista Allan Sieber, que também publica na Ilustrada, Montanaro "fez o trabalho dele e a escolha da ilustração valeu a pena".

[...]

"As pessoas ligam a palavra 'charge' a coisas alegres, mas a ideia é ser um convite ao pensamento", diz o quadrinista Mauricio de Sousa.

O jornalista e professor de letras da Unifesp (Universidade Federal de São Paulo) Paulo Ramos concorda. "Quem está acostumado entende melhor desenhos como o de Montanaro. Outros veem as charges como necessariamente uma piada e, por isso, se incomodam".

Para Jal, presidente da Associação dos Cartunistas do Brasil, "é nesses momentos de tragédia que temos de fazer críticas".

Diogo Bercito

$23 / 03 / 2011$ 
A partir da discussão, foi solicitado aos professores que transformassem essa situação em pauta em uma crônica. A sugestão foi vivenciar a situação para, posteriormente, levar a proposta para a sala de aula.

\section{Prática 2}

Começamos o segundo encontro com os professores, que ocorreu aproximadamente um mês após o primeiro, com questionamentos a partir do trabalho proposto de aplicação da escrita de uma crônica:

Os alunos produziram e, agora, o que fazer com o texto?

O que é interferir em um texto? Como?

Olhar a gramática?

Olhar as ideias? De acordo com meus valores? Todos devem ter o mesmo ponto de vista na sala de aula? Falar de um mesmo lugar?

Retomamos, nesta conversa, as ideias sobre as condições de produção contidas no item 1.3 deste artigo. O que ficou bem definido a partir do diálogo foi a riqueza que o trabalho oferece ao se considerar toda a heterogeneidade presente na sala de aula.

Foi também eixo de diálogo a teoria explanada no item 1.2. Chegamos à conclusão de que o agrupamento proposto pelos pesquisadores de Genebra - que pode ser discutido e aprimorado $^{13}$ - constitui um ponto de partida para que pensemos em uma progressão curricular ao longo do ensino fundamental ${ }^{14}$. Por exemplo, em um determinado momento, os alunos vivenciam uma sequência didática ${ }^{15}$ com um dos gêneros do grupo narrar; em seguida, passam a outra sequência, trabalhando com um gênero do grupo expor; depois, passam a outra sequência, trabalhando com um gênero do grupo descrever ações, etc. Em outra etapa, inicia-se novamente o percurso, só que desta vez explorando gêneros diferentes dos mesmos grupos, de acordo com o grau de dificuldade dos gêneros, com a faixa-etária dos alunos e com as capacidades que se pretende desenvolver. Reconhecemos que essa forma de trabalho parece retomar a seriação, a graduação, mas o diferencial é que retomamos com a consciência de que esse "planejamento" prévio é impossível de escalonar nas práticas discursivas reais (GIOVANI, 2010).

Reforçando a teoria dos autores de que este trabalho deva ocorrer em espiral no decorrer do ano e das séries, levamos um exemplo de trabalho com gêneros da ordem do argumentar, especificamente, com o texto de opinião.

Questionamos sobre quem conhecia a história "Os três porquinhos" e pedimos para que os professores presentes recuperassem a narrativa. Após, questionamos se eles conheciam 
o outro lado da história, ou seja, a versão contada sob a ótica do Lobo Mau. Diante das respostas negativas, fizemos a leitura da história "A verdadeira história dos três porquinhos", de Jon Scieszka, traduzido por Pedro Maia.

Separamos a turma em dois grupos e simulamos um tribunal ${ }^{16}$, no qual cada lado defendia - apresentando argumentos - um lado da história. A princípio, a turma que ficou responsável por defender o lobo ficou um pouco desconfortável, até porque estavam argumentando contra a ideologia dominante. Arrumar argumentos para defender um lado da história que até o momento era acusado foi difícil. No entanto, no diálogo corrente, os argumentos a favor e contra o lobo e os porquinhos foram aparecendo e foram cada vez mais sendo justificados.

Um dos professores ficou responsável por ser o juiz e decidir o grupo que melhor argumentou. Depois da escolha, pedimos que os grupos trocassem de posição. Quem anteriormente havia defendido os porquinhos defenderia $o$ lobo e vice-versa. Essa mudança causou outro desconforto, porque outros argumentos precisaram aparecer e, a essa altura, já era consenso que a opinião individual pouco importava diante da importância de defender $o$ grupo do qual se fazia parte.

Foi uma atividade muito estimulante, uma vez que foi possível observar os professores envolvidos, falando ao mesmo tempo, com empolgação, ocupando a real condição de alunos. Enfatizamos a importância do argumentar e da justificativa para sustentar um posicionamento. Para finalizar, solicitamos que cada um escrevesse um texto de opinião, defendendo um lado da história. A sugestão foi levar a atividade para a sala de aula.

\section{Considerações finais}

Este artigo teve o intuito de relatar o diálogo instaurado entre nós - pesquisadores - e professores, durante dois encontros de um curso de formação ofertado pelo Pibid. Durante o curso, tivemos por objetivo mostrar a importância do texto no processo de ensino/aprendizagem de Língua Portuguesa.

O que se tentou esclarecer - através do diálogo concreto entre teoria/prática é que a proposta de se trabalhar o texto em sala de aula - proposta, inclusive, presente nos documentos oficiais de ensino - é uma resposta às necessidades das novas compreensões sobre lingua(gem) presentes no final da modernidade, além de ser uma tentativa de superar um fracassado modelo estruturalista de ensino da língua.

O texto concebido como ponto de partida e de chegada do processo de ensino/ aprendizagem da lingua(gem) requer que se assumam concepções dialógicas 
de linguagem, assim como uma concepção de texto também dialógica. O que isso quer dizer?

Quer dizer que falar em texto é falar de sujeitos que, organizados socialmente, fazem deste um acontecimento da vida. Assim, não tem como olhar para um texto descolado do seu contexto e dos sujeitos criadores. Dessa forma, tentamos realizar atividades em que mostramos toda a heterogeneidade inerente ao texto ${ }^{17}$. Ainda que cada encontro focasse a escrita de um gênero específico, ele não foi o único elencado para o diálogo. No primeiro encontro, por exemplo, dialogamos com a crônica e com alguns gêneros que circulam no suporte jornal, como a charge e a carta do leitor. No segundo encontro, fizemos dialogar uma narrativa com textos da ordem do argumentar. Tentamos também salientar a riqueza do trabalho, contemplando gêneros tanto escritos como orais.

Através de propostas de atividades escritas realizadas com os professores em formação, pensamos ter ficado clara a ideia de que não se pode homogeneizar o trabalho com a linguagem. Isso porque ela faz parte da vida. Bakhtin (2003, p. 268), ao referir-se aos gêneros do discurso, diz que eles são "as correias de transmissão entre a história da sociedade e a história da linguagem”. Portanto, não há como dissociar gênero discursivo e vida.

Finalizamos tomando emprestadas as palavras de Miotello e Couvre (2008, p. 03): "a escola das nuvens, lugar de formação de um não-lugar, tem que ser destruída, e ceder lugar a uma escola onde cabe a vida". É essa perspectiva que deve ter espaço na vida, especialmente, nas aulas de língua portuguesa, na escola.

\section{The teaching/learning of the Portuguese Language from the genres of discourse}

\section{Abstract}

The present article is born from a continuing education course offered by Pibid of the Federal University of Pampa (Unipampa) to the Portuguese language teachers of the Bagé-RS public network. The purpose of the training entitled "The teaching/learning of the Portuguese language from the discourse genres" was to reflect on the importance that the text occupies in the teaching / learning process of the Portuguese language. For this, we return to some theoretical points such as: i) the change from the nomenclature of the writing to the production of text and the meaning that each of the terms includes; ii) the understanding of genres from Bakhtin (2003) and didactic transposition, according to Schneuwly and Dolz (2004); iii) the importance of thinking about the production conditions of any and all text. Finally, the teachers had practical writing activities based on the theory and that showed that working with the text is to let 'life' invade the space of the classroom.

Keywords: Teaching/learning of Portuguese Language. Discourse genres. Didactic sequence. 


\section{Notas}

1 A respeito, ver Marinho (2001).

2 Concepção de linguagem ligada à teoria da comunicação que vê a língua como código.

3 Pibid do Curso de Letras da Universidade Federal do Pampa (Unipampa), Campus Bagé, RS.

4 Bakhtin (2004) vai dizer que a palavra é o signo neutro por excelência. Giovani (2006) aponta que a palavra é plurissignificativa, sendo o contexto o responsável por fechar os seus sentidos possíveis. Dessa forma, quando o contexto fecha um sentido da palavra, esta não deixa de possuir os seus vários outros sentidos, pois estes estarão presentes como uma aura da palavra que não cabem em dada situação, mas que não deixam de existir.

5 Geraldi (2004b) afirma que aceitar a interação verbal como fundante do processo pedagógico é deslocar-se continuamente de planejamentos rígidos para programas de estudos elaborados no decorrer do próprio processo de ensino/ aprendizagem.

6 Na nova situação a gramática também tem o seu espaço, mas o trabalho com ela ocorre de uma forma diferente. São as chamadas atividades epilinguísticas. A respeito, ver Geraldi (2002).

7 Geralmente, apresenta-se um cenário no qual personagens - em um tempo e um espaço determinado - criam uma situação que incitará numerosas aventuras (complicação/resolução) até chegar-se a um desfecho.

8 É importante atentar-se para o fato de que os autores denominam o agrupamento como "proposta provisória", ou seja, se é proposta e provisória, está sujeito a intervenções e contra-palavras dos leitores.

$9 \quad$ Sem apagar a heterogeneidade que pode constituir alguns gêneros.

10 Essa atitude vicia o aluno a escrever a partir do que acredita que o professor gostará. Fará o texto com base na imagem que cria do "gosto" e da visão de língua do professor.

$11 \mathrm{Na}$ discussão, surgiu a ideia de que o cronista costuma ter a atenção voltada para fatos do dia a dia ou veiculados em notícias de jornal e os registra com humor, sensibilidade, crítica e poesia; ademais, falou-se sobre o objetivo desse texto: entreter os leitores e, ao mesmo tempo, levá-los a refletir criticamente sobre a vida e os comportamentos humanos.
12 A opção do garoto foi reaproveitar um símbolo da cultura japonesa: a xilogravura de Katsushika Hokusai.

13 Os próprios autores denominam-na por "provisória".

14 Levando-se em conta a necessidade de se trabalhar em espiral, em todos os níveis escolares, gêneros dos diferentes grupos.

15 Os autores definem sequência didática como um conjunto de atividades escolares organizadas de maneira sistemática, em torno de um gênero textual oral ou escrito (SCHNEUWLY; DOLZ, 2004, p. 97).

16 Na verdade, recuperamos, com essa atividade, a argumentação oral que circula na esfera de um tribunal (que, no caso, era conhecido pelos professores). Foi intencional selecionar o trabalho com um gênero de caráter oral porque os gêneros orais também devem ser foco do processo ensino/aprendizagem. Mesmo assim, houve uma proposta de escrita ao final das atividades.

17 A respeito, ver Corrêa (2004).

\section{Referências}

BAKHTIN, M. Estética da criação verbal. São Paulo: Martins Fontes, 2003.

BAKHTIN, M. Marxismo e filosofia da linguagem. São Paulo: Hucitec, 2004.

BRASIL, Secretaria de Educação Fundamental. Parâmetros curriculares nacionais: introdução aos parâmetros curriculares nacionais. Brasília, DF: MEC/SEE, 1997.

BRITTO, L. P. L. A escola: o grande interlocutor. In: GERALDI, J. W. (org.). O texto na sala de aula. São Paulo: Ática, 2004. p. 118-121.

CORRÊA, M. L. G. O modo heterogêneo de constituição da escrita. São Paulo: Martins Fontes, 2004.

GERALDI, J.W.; CITELLI, B. Aprender $e$ ensinar com textos de alunos. São Paulo: Cortes, 2004. v.1.

GERALDI, J. W. O texto na sala de aula. São Paulo: Ática, 2004a. 
GERALDI, J. W. A aula como acontecimento. Portugal: Universidade de Aveiro; Campus de Santiago, 2004b.

GERALDI, J. W. Portos de passagem. São Paulo: Ática, 2002.

GIOVANI, F. A ontogênese dos gêneros discursivos escritos na alfabetização. 2010. 237 f. Tese (Doutorado em Linguística e Língua Portuguesa) - Universidade Estadual Paulista Júlio de Mesquisa Filho, Araraquara, 2010.

GIOVANI, F. O texto na apropriação da escrita. 2006. 137 f. Dissertação (Mestrado em Educação) - Departamento de Metodologia de Ensino, Universidade Federal de São Carlos, São Carlos, 2006.

LEMOS, C. Redações de vestibular: algumas estratégias. Cadernos de Pesquisa, São Paulo, n. 23, 1977.

MARINHO, M. A oficialização de novas concepções para o ensino de português no Brasil. 2001. Tese (Doutorado em Linguística) - Instituto de Estudos de Linguagem, Universidade Estadual de Campinas, Campinas, 2001.

MIOTELLO, V.; COUVRE, A. O conceito de gêneros do discurso e a filosofia bakhtiniana de linguagem. Linguasagem, São Carlos, 2008.

OSAKABE, H. O sujeito do discurso. In: GERALDI, J. W. (org.). O texto na sala de aula. São Paulo: Ática, 2004. p. 26-27.

OSAKABE, H. Redações no vestibular: provas de argumentação. Cadernos de Pesquisa, n. 23, p. 51-59, 1977.

PIETRI, E. A constituição da escrita escolar em objeto de análise dos estudos linguísticos. Trabalhos em Linguística Aplicada, Campinas, v. 46, n. 2, p. 283-287, jul./dez. 2007.

RIO GRANDE DO SUL. Secretaria de Estado de Educação. Departamento Pedagógico. Lições do Rio Grande: referencial curricular para as escolas estaduais. Porto Alegre: SE/ DP, 2009. V. 1
ROJO, R. A prática de linguagem em sala de aula - praticando os PCNs. São Paulo: Mercado de Letras, 2006.

SCHNEUWLY, B.; DOLZ, J. Gêneros orais e escritos na escola. Campinas, SP: Mercado de Letras, 2004. 